\title{
AVALIAÇÃO DO USO DE SITE PARA INTERAÇÃO CURSO X PROFESSOR X ALUNO: CASO DO CURSO DE CIÊNCIAS CONTÁBEIS DA UNEMAT - CAMPUS DE TANGARÁ DA SERRA
}

\author{
Laércio Juarez Melz ${ }^{1}$ \\ Cleiton Franco $^{2}$ \\ Karine Medeiros Anunciato ${ }^{3}$ \\ Eugênio Carlos Stieler ${ }^{4}$ \\ Adielson Gonçalves de Lima ${ }^{5}$
}

\section{RESUMO}

O objetivo da pesquisa foi avaliar o uso do site como forma de interação entre o Curso, professores e alunos do curso de Ciências Contábeis da UNEMAT - campus de Tangará da Serra. A pesquisa caracteriza-se quanto aos objetivos como descritiva. Quanto aos procedimentos, foi utilizada pesquisa bibliográfica, estudo de caso, survey. Foram analisados dados de acesso e permanência no site e foi aplicado questionário de avaliação, obtendo-se 234 respostas. O período analisado foi julho de 2010 a junho de 2012. Conclui-se que o número de acessos tem aumentado ao longo dos meses analisados, principalmente no período letivo. O site foi bem avaliado na maioria dos quesitos respondidos, principalmente no que tange à simplicidade e clareza e à organização dos conteúdos.

Palavras-chave: Contabilidade. Ciência da Informação. Ensino Superior.

\section{INTRODUÇÃO}

O uso da tecnologia facilitou grandemente a difusão do conhecimento. Inúmeras foram as aplicações dadas aos instrumentos de computação. A informação e o conhecimento são hoje o eixo central do desenvolvimento social, e isso ainda mais nos países do chamado Terceiro Mundo, em países como a Colômbia, nos quais uma industrialização precária não impede que estejamos entrando numa sociedade cuja competitividade produtiva depende mais da informação e do conhecimento do que das máquinas, mais da inteligência do que da força (BARBERO, 2000).

Estima-se que, no ano de 2011, encontram-se mais de 35 milhões de internautas em território nacional, que representam aproximadamente $18 \%$ do total da população do país. Esses internautas consomem em média 34 horas mensais de navegação (CETIC, 2011), o que faz com que o Brasil ocupe a $5^{\mathrm{a}}$ colocação no ranking mundial de conexões à internet (ANTONIOLI, 2011).

\footnotetext{
1 Mestre em Engenharia de Produção (UFSCar), Professor do Departamento de Ciências Contábeis da UNEMAT- Campus de Tangará da Serra, Coordenador do NEPEC, e-mail: laercio@unemat.br.

${ }^{2}$ Mestre em Agronegócios e Desenvolvimento Regional (UFMT), Professor do Departamento de Ciências Contábeis da UNEMAT- Campus de Tangará da Serra, e-mail: cleitonfranco@unemat.br

${ }^{3}$ Mestre em Agricultura Tropical (UFMT), Professora do Professor do Departamento de Ciências Contábeis da UNEMAT- Campus de Tangará da Serra, e-mail: karine@unemat.br

${ }^{4}$ Mestre em Ensino de Física e Matemática (UNIFRA), Professor do Departamento de Ciências Contábeis da UNEMAT- Campus de Tangará da Serra, e-mail: eugenio@unemat.br

${ }^{5}$ Bolsista do NEPEC, Acadêmico do curso de Ciências Biológicas (UNEMAT).
} 


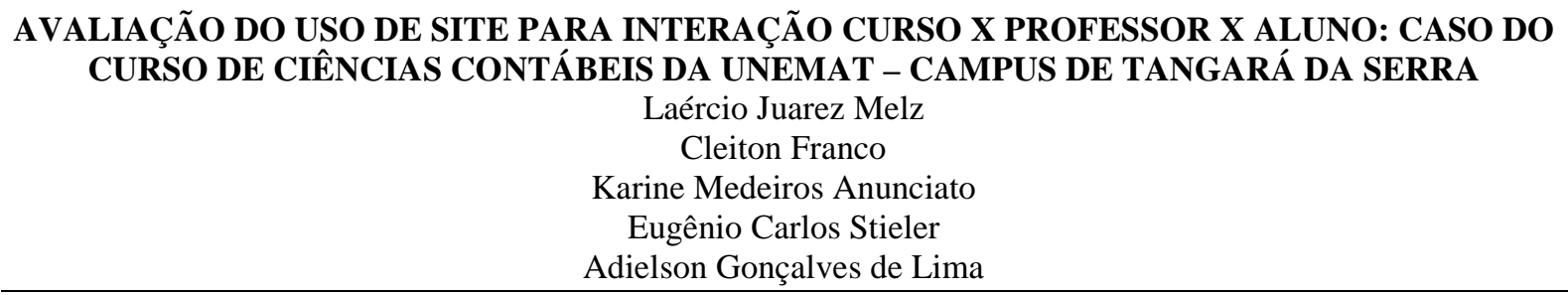

Ao realizar a análise do número de internautas conectados e suas respectivas horas navegadas, se considerado o ambiente de trabalho agregado ao ambiente domiciliar, o número de navegadores cresce para mais de 43 milhões. A maioria destes internautas passam aproximadamente 48 horas conectados por mês, representando assim, aproximadamente $20 \%$ do total de horas/mês (CETIC, 2011). Segundo o Ibope (2011, apud CETIC, 2011) aproximadamente 51,88\% dos internautas brasileiros são do sexo masculino enquanto aproximadamente $48,12 \%$ pertencem ao sexo feminino.

O objetivo da pesquisa foi avaliar o uso do site como forma de interação entre o Curso, professores e alunos do curso de Ciências Contábeis da UNEMAT - campus de Tangará da Serra. Especificamente pretendeu-se: a) apresentar dados quantitativos sobre a evolução do uso do site ao longo dos meses desde julho de 2010 até junho de 2012; b) apresentar o fluxo de acessos dos usuários no site; c) apontar a avaliação dos professores e alunos usuários do site.

\section{REFERENCIAL TEÓRICO}

\subsection{Características de um website}

$\mathrm{O}$ advento da internet ofereceu grande capacidade para armazenamento de dados. $\mathrm{O}$ acesso às informações na internet é realizado por meio dos websites. Website é o conjunto de páginas hospedadas em um servidor de internet para acesso ao público. O desenvolvimento do website deve atender às necessidades dos seus usuários finais. Conforme Redig (2006), o projeto de design deve ter como objetivos:

1. Atender aos usuários;

2. Explorar o problema de forma abrangente, trabalhar de forma sistêmica e sistemática, conciliar questões humanas e técnicas;

3. Detectar e corrigir erros durante o processo;

4. Procurar solução diversa das existentes, experimentar;

5. Incrementar a durabilidade do produto ou sistema gerado.

O projeto de um site deve visar seu público alvo. Os usuários da internet podem ser classificados em iniciantes, intermediários e avançados. Os usuários iniciantes têm necessidades especiais em relação ao uso do sistema. Para estes usuários, a navegação deve ser simples. Usuários intermediários buscam maiores informações, exploram melhor as 
AVALIAÇÃO DO USO DE SITE PARA INTERAÇÃO CURSO X PROFESSOR X ALUNO: CASO DO

CURSO DE CIÊNCIAS CONTÁBEIS DA UNEMAT - CAMPUS DE TANGARÁ DA SERRA

Laércio Juarez Melz

Cleiton Franco

Karine Medeiros Anunciato

Eugênio Carlos Stieler

Adielson Gonçalves de Lima

páginas. Usuários avançados são os que não encontram dificuldades no uso das páginas do website. É necessário que, no projeto do website, atenda-se a todos os usuários da informação. Nielsen (1992) afirma que o projeto de um sistema informatizado deve ter:

1. Simplicidade e clareza no diálogo;

2. O sistema deve falar a língua do usuário;

3. Minimizar a carga na memória do usuário;

4. Consistência;

5. Feedback;

6. Saídas do sistema claramente sinalizadas;

7. Permissão de shortcuts de diálogo;

8. Mensagens de erro adequadas;

9. Prevenção de erros;

10. Help on-line e documentação sobre o sistema.

A navegabilidade do website é fator importante. Navegabilidade significa facilidade de acesso em todas as páginas do site. Mayhew (1992), afirma que o design de interfaces deve seguir os seguintes princípios:

1. Compatibilidade com o usuário;

2. Compatibilidade entre produtos;

3. Compatibilidade com a tarefa a ser realizada;

4. Compatibilidade com o fluxo do trabalho;

5. Consistência;

6. Familiaridade;

7. Simplicidade;

8. Interface de manipulação direta;

9. Controle do usuário sobre o sistema;

10. Flexibilidade;

11. Apresentação do resultado e do andamento dos processos;

12. Tecnologia invisível;

13. Robustez técnica;

14. Proteção contra erros;

15. Facilidade de aprendizado, entendimento e utilização. 
AVALIAÇÃO DO USO DE SITE PARA INTERAÇÃO CURSO X PROFESSOR X ALUNO: CASO DO

CURSO DE CIÊNCIAS CONTÁBEIS DA UNEMAT - CAMPUS DE TANGARÁ DA SERRA

Laércio Juarez Melz

Cleiton Franco

Karine Medeiros Anunciato

Eugênio Carlos Stieler

Adielson Gonçalves de Lima

Princípios de ergonomia também podem ser utilizados para o desenvolvimento de websites. Bastien e Scapin (1993) estabelecem oito critérios ergonômicos que deveriam ser seguidos no processo de composição da interface humano-computador:

1. Condução;

2. Carga de trabalho;

3. Controle explícito;

4. Adaptabilidade (flexibilidade/experiência);

5. Gestão de erros (proteção/correção);

6. Homogeneidade/consistência;

7. Significado de códigos e denominações;

8. Compatibilidade (usuário/tarefa/contexto).

Fleming (1998) sugerem alguns princípios para o design de sistemas de navegação:

1. Sistema de navegação fácil de aprender;

2. Manter-se constante;

3. Proporcionar feedback;

4. Aparecer em contexto;

5. Oferecer alternativas;

6. Ser econômico em termos de ações e tempo;

7. Disponibilizar mensagens visuais claras;

8. Utilizar rótulos claros e inteligíveis;

9. Ser apropriado ao propósito do site;

10. Fornecer suporte às metas e comportamentos dos usuários.

No desenvolvimento, deve-se considerar aspectos funcionais, estéticos e cognitivos, considerando o público alvo. Petterson (2007) enumeram outros princípios para o design de sistemas de informação:

1. Princípios funcionais:

a. Estrutura;

b. Simplicidade;

c. Clareza;

d. Ênfase;

e. Unidade. 


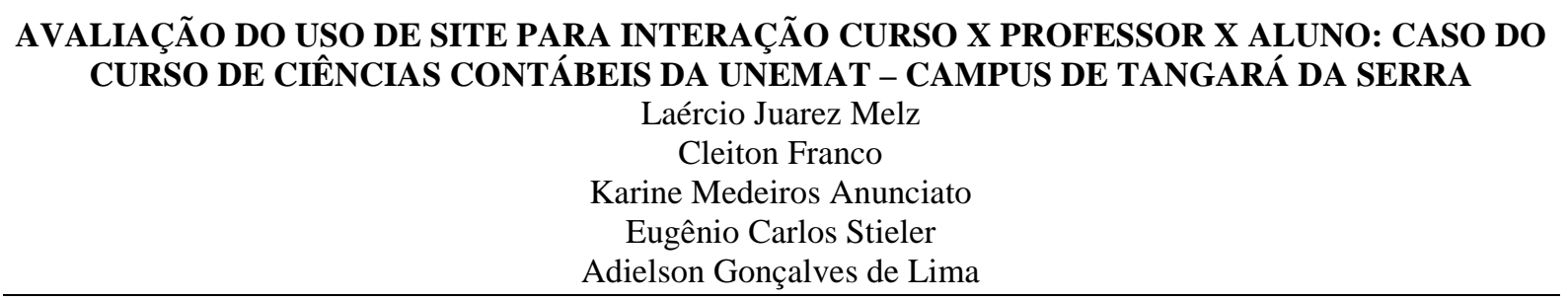

2. Princípios estéticos:

a. Harmonia;

b. Proporção estética.

3. Princípios cognitivos:

a. Atenção/Percepção;

b. Processamento;

c. Memória.

Rosenfeld e Morville (1998) fazem algumas recomendações para arquitetura da informação:

1. Recomendações para organização:

a. Categorias mutuamente excludentes;

b. Uso de termos não ambíguos;

c. Classificação por conteúdo e não por granularidade ou

2. Formato de apresentação;

a. Equilíbrio entre largura e profundidade;

b. Equilíbrio entre hierarquia e hipertextualidade.

3. Recomendações para rotulagem:

a. Uso de termos não ambíguos;

b. Expressões curtas;

c. Não utilização de vocabulário "interno ao grupo";

d. Ícones devem ser rotulados.

4. Recomendações para navegação:

a. Onde estou?

b. De onde vim?

c. Para onde posso ir a partir daqui?

d. Permitir navegação lateral e vertical direta;

e. Uso moderado de links embutidos.

5. Recomendações para sistema de busca:

a. Permitir diferentes formas de busca;

b. Permitir diferentes níveis (básico, avançado);

c. Apresentar as informações da busca de forma consistente com o restante do site; 


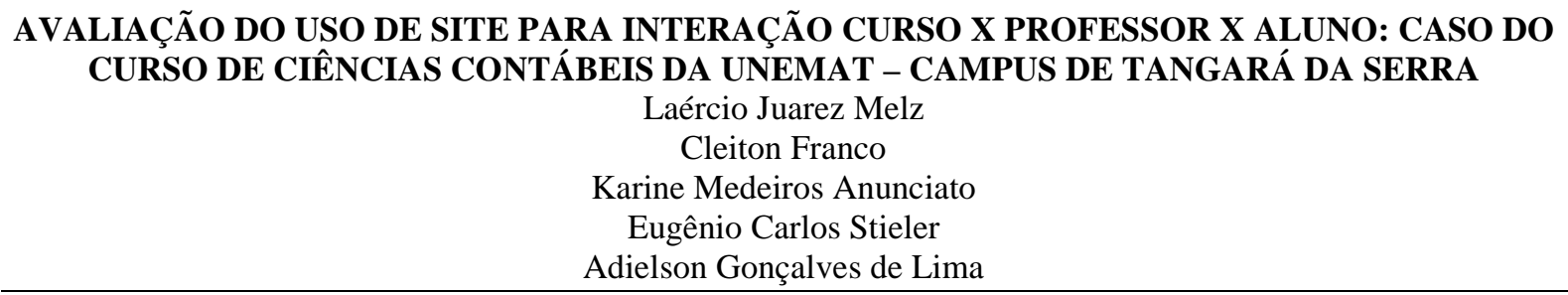

d. Permitir que o usuário escolha o nível de detalhamento dos resultados, a quantidade de resultados e a ordem de apresentação;

e. Providenciar busca default de modo que o usuário não necessite configurar nada.

\subsection{Metodologia de ensino e o uso do computador no ensino superior}

Conforme a ideologia de Nérici (1992) didaticamente, método é forma como serão traçados os caminhos a serem percorridos a fim de que os objetivos possam ser alcançados. Desta maneira, metodologia de ensino nada mais é do que a forma como ocorre a transmissão de informação e aprendizado do professor para o aluno. Quando voltada para o ensino superior em contabilidade a metodologia de ensino assume a vertente de ser uma forma de transmissão de conhecimento a fim de que estes sejam aplicados a realidade das empresas (MARION; MARION, 2006).

Depende da escolha de uma boa metodologia o sucesso do aprendizado e para tal é necessário que a mesma seja envolvente a atrativa para o público alvo. Segundo o que descreve Marion e Marion (2006) normalmente o que encontra-se presente em sala de aula é metodologia de ensino bastante rígida, não tão atrativa, na qual o aluno apenas recebe a informação que é transmitida pelo professor. $\mathrm{O}$ aluno assume portanto, posição passiva no ciclo de aprendizagem. Dentro desta perspectiva de pensamento, Marion e Marion (2006) defendem, ainda, que deve haver a busca de inovação na transmissão de conhecimento. $\mathrm{Na}$ qual, o aluno possa assumir a posição ativa do aprendizado, para que assim possa ter chances de participar ativamente das análises propostas e seja forçado a expressar suas opiniões, tornando o processo mais interativo e dinâmico. É justamente neste meio que pode ser inserido o uso da informática e consecutivamente o uso da internet. Isso, agilizaria e modernizaria a prática do ensino, pois, é evidente o fato de que a metodologia de ensino deve ser constantemente atualizada para não perder a atenção daqueles que estão envolvidos no processo. Para Nérici (1992):

\footnotetext{
A metodologia do ensino deve ser encarada como um meio e não como um fim, pelo que deve haver, por parte do professor, disposição para alterá-la, sempre que sua crítica sobre a mesma o sugerir. Assim, não se deve ficar escravizado à mesma, como se fosse algo sagrado, definitivo, imutável.
} 


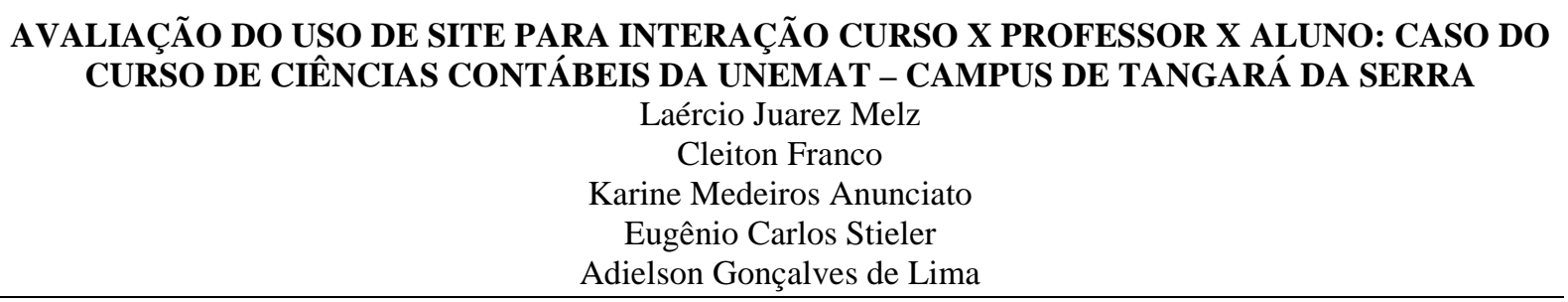

Uma metodologia de ensino deve ser composta de três fases: Planejamento, Execução e Avaliação. Nessas fases são compreendidas tarefas como definição da política de ensino e seu conteúdo, execução dos planos traçados e análise a fim de se obter a verificação se os objetivos inicialmente traçados foram atingidos (NÉRICI, 1992).

Para Godoy, (1997), "Embora os professores façam uso constante do computador para realizar suas pesquisas e trabalhos individuais, poucos se lembram dele enquanto recurso para o ensino". Godoy (1997) define desta forma o que ocorre com a maioria dos docentes. Embora a evolução tecnológica cresça dia após dia, influenciando cada vez mais toda a população, esse crescimento não tem sido acompanhado pelas universidades brasileiras.

Um dos maiores ponto de discussão sobre o aceite ou não da inclusão da internet e suas ferramentas no ensino do meio acadêmico esta no fato dele apresentar algumas desvantagens ditas como relevantes por estudiosos da área.

Segundo Godoy (1997), a internet faz com que se perca a vivacidade social existente entre as pessoas, pois, tudo torna-se muito frio e impessoal. Fica evidente, contudo, que o uso da internet faz com que a troca de informação ocorra de maneira muito mais ágil e eficiente, auxiliando no rápido processamento de idéias (RUSHBY, 1985 Apud MOREIRA, 1997).

É justamente na busca de se correlacionar o crescimento da informação disponível ao alcance de todos de forma rápida através da internet que surgem aos poucos à idéia de se agregar as redes sociais ao meio de ensino. Exemplo, que segundo Moran (1997) é o encontrado na Escola do Futuro, grupo de pesquisa da Universidade de São Paulo pioneiro na área de desenvolvimento de projetos relacionados ao ensino de ciências e humanidades através de redes telemáticas no ensino fundamental e médio, desde 1990. Os resultados obtidos com processos avaliativos, demonstram que a prática adotada aumenta o interesse e a motivação do aluno para o desenvolver da pesquisa, a sensibilidade para o uso de novas tecnologias, para a busca por novas amizades e pelo estudo da língua inglesa. A maior dificuldade enfrentada pelo projeto está em promover a continuidade especialmente na rede pública brasileira, por deficiência em equipamentos e professores que possam monitorar o projeto (MORAN, 1997).

Defensor desta bandeira, Valente (2011), descreve que práticas como a desenvolvida no projeto Escola do Futuro e a inserção das redes sociais podem e devem ser utilizadas no ambiente escolar e conseqüentemente acadêmico como forma de agregação ao currículo e a 


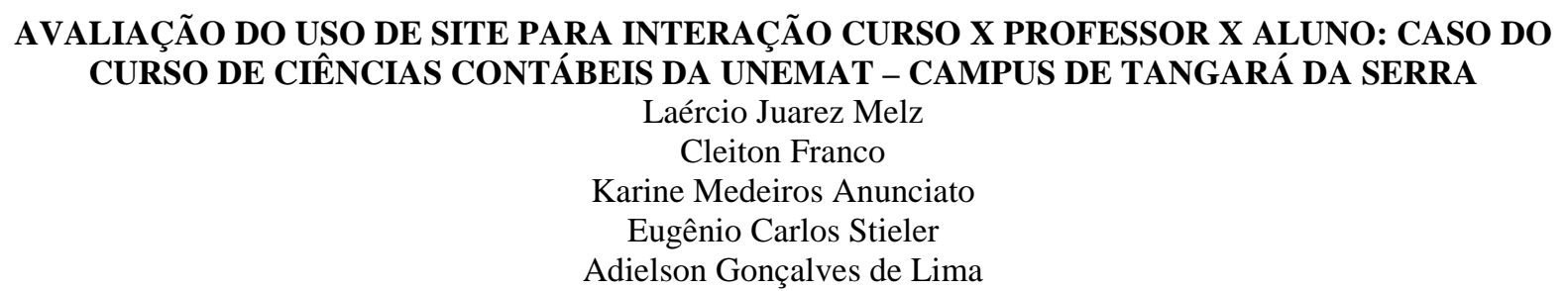

proposta de aprendizado, desde que, todo este desenvolver apresente a intervenção de um gestor, como forma de orientar e verificar se os objetivos propostos estão sendo buscados. Pois, em toda navegação e consecutivamente toda pesquisa realizada em um ambiente virtual é necessário utilizar-se de um censo crítico ao filtrar informações ditas como relevantes ou não.

\section{METODOLOGIA}

A pesquisa caracteriza-se quanto aos objetivos como descritiva, pois, busca descrever o acesso e avaliar o site (RAUPP, MAURY e BEUREN, 2003). Quanto aos procedimentos, foi utilizada pesquisa bibliográfica, estudo de caso, survey (RAUPP, MAURY e BEUREN, 2003). Foi utilizada pesquisa bibliográfica para estabelecer o contexto do uso da internet no Brasil, as características de um website e como a internet e o uso do computador podem auxiliar no processo de ensino-aprendizagem.

Considera-se estudo de caso, conforme Yin (1994), porque procurou evidenciar as características e os resultados de avaliação de um site específico: o site do Departamento de Ciências Contábeis da UNEMAT - campus de Tangará da Serra. O site foi postado nos endereços: http://tangara.unemat.br/contabeis e http://www2.unemat.br/contabeistga. Os resultados foram obtidos por meio dos recursos do Google Analytics ${ }^{\circledR}$ oferecido gratuitamente pelo Google. Os dados selecionados foram: número de visitas, número de visitantes únicos, visualizações de páginas, páginas por visita, páginas por visitante, duração média da visita, porcentagem de novas visitas. Todos os dados foram apresentados por mês e ano desde julho de 2010 até junho de 2012. Segundo GOOGLE (2012) "O Google Analytics é criado a partir de uma plataforma de relatório eficiente e fácil de usar para que você possa decidir quais dados deseja exibir e personalizar seus relatórios com apenas alguns cliques”.

A pesquisa aplicou survey para coleta da opinião dos visitantes do site por questionário auto-administrado (MARTINS e FERREIRA, 2011). Foi disponibilizado questionário com 3 questões fechadas e uma aberta no próprio site do curso, obtendo respostas no período de 20/06/2010 até 18/06/2012 (Quadro 1). As questões de avaliação utilizaram que variava de 1 a 5 . Esta escala foi convertida para análise qualitativa, sendo 1=Péssimo, 2=Ruim, 3=Regular, 4=Bom e 5=Ótimo. 


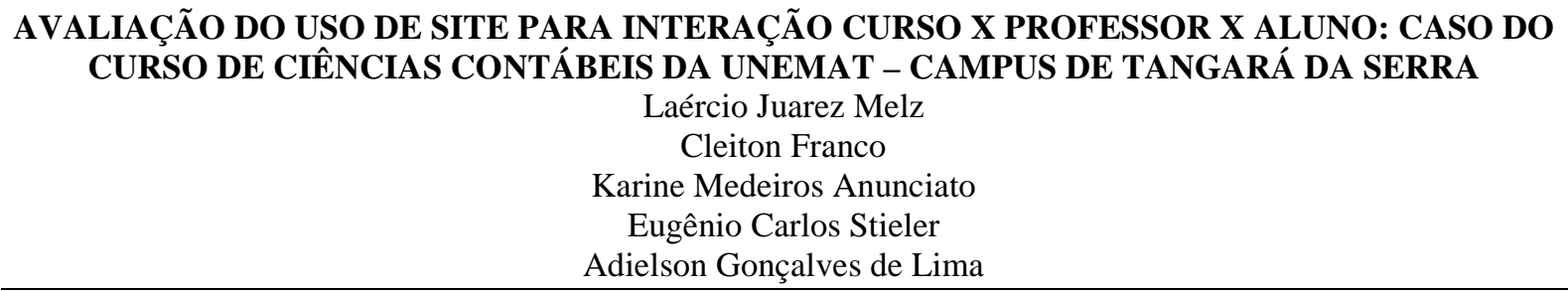

\begin{tabular}{|c|c|}
\hline \multicolumn{2}{|c|}{ Quadro 1 - Questões disponíveis no questionário aplicado. } \\
\hline Questão & Respostas \\
\hline 1. Você é um usuário de internet: & $\begin{array}{l}\text { Iniciante } \\
\text { Intermediário } \\
\text { Avançado }\end{array}$ \\
\hline 2. Qual o seu vínculo com o Departamento? & $\begin{array}{l}\text { Acadêmico } \\
\text { Professor } \\
\text { Não possui vinculo }\end{array}$ \\
\hline \multicolumn{2}{|c|}{ 3. Como você avalia o site em relação aos itens abaixo? (1=Péssimo e 5=Ótimo)* } \\
\hline Simplicidade e clareza & (1=Péssimo e 5=Ótimo) \\
\hline Organização dos conteúdos & (1=Péssimo e 5=Ótimo) \\
\hline Aparência & (1=Péssimo e 5=Ótimo) \\
\hline Divulgação de ações do Departamento & (1=Péssimo e 5=Ótimo) \\
\hline Disponibilidade de materiais & (1=Péssimo e 5=Ótimo) \\
\hline Balcão de empregos & (1=Péssimo e 5=Ótimo) \\
\hline Publicações & (1=Péssimo e 5=Ótimo) \\
\hline Informações sobre o curso & (1=Péssimo e 5=Ótimo) \\
\hline 4. Deixe sua sugestão para melhorar o site: & Questão aberta \\
\hline
\end{tabular}

O questionário é outro recurso gratuito oferecido pelo Google, o Google Drive ${ }^{\circledR}$. Este recurso permite a coleta de dados em forma de formulário que pode ser processado em planilha eletrônica. "Google Drive is everywhere you are-on the web, in your home, at the office and on the go. So wherever you are, your stuff is just...there. Ready to go, ready to share. Get started with 5 GB free" (GOOGLE, 2012b). No total foram 234 respostas entre os dias 20/06/2010 e 18/06/2012, concentrando-se 34 respostas em julho, segundo mês de avaliação. Do total foram 202 de acadêmicos, 23 não vinculados e 9 professores. O curso tem 400 alunos e 25 professores lotados (CONTÁBEIS, 2012).

Tabela 1 - Quantidade de respostas ao questionário por mês, jun-2010 a jun/2012.

\begin{tabular}{c|c|c|c|c}
\hline Meses & $\mathbf{2 0 1 0}$ & $\mathbf{2 0 1 1}$ & $\mathbf{2 0 1 2}$ & Total Mês \\
\hline Jan & & 6 & 2 & 8 \\
\hline fev & & 12 & 6 & 18 \\
\hline mar & & 6 & 9 & 13 \\
\hline abr & 3 & 9 & 5 & 12 \\
\hline mai & 18 & 8 & & 31 \\
\hline jun & 34 & 7 & & 41 \\
\hline jul & 22 & 14 & & 21 \\
\hline ago & 11 & 10 & & 9 \\
\hline set & 6 & 3 & & 22 \\
\hline out & 15 & 7 & & 11 \\
\hline nov & 7 & 4 & $\mathbf{3 2}$ & \\
\hline dez & $\mathbf{1 1 3}$ & $\mathbf{8 9}$ & & $\mathbf{2 3 4}$ \\
\hline Total Ano & & & & \\
\hline
\end{tabular}


AVALIAÇÃO DO USO DE SITE PARA INTERAÇÃO CURSO X PROFESSOR X ALUNO: CASO DO

CURSO DE CIÊNCIAS CONTÁBEIS DA UNEMAT - CAMPUS DE TANGARÁ DA SERRA

Laércio Juarez Melz

Cleiton Franco

Karine Medeiros Anunciato

Eugênio Carlos Stieler

Adielson Gonçalves de Lima

Quanto à abordagem do problema, trata-se de pesquisa qualitativa, dado o caráter avaliativo. Também não foram empregados tratamentos estatísticos tais como cálculo de amostra, pois, o questionário de avaliação foi de livre adesão dos participantes. Percebe-se que o nível que os respondentes afirmara ter fica entre o intermediário e o avançado (Tabela 2).

Tabela 2 - Nível de conhecimento em informática dos usuários que responderam ao questionário.

\begin{tabular}{c|c|c|c|c}
\hline Níveis & $\mathbf{2 0 1 0}$ & $\mathbf{2 0 1 1}$ & $\mathbf{2 0 1 2}$ & Total Geral \\
\hline Avançado & 39 & 37 & 14 & 90 \\
\hline Iniciante & 28 & 20 & 11 & 59 \\
\hline Intermediário & 46 & 32 & 7 & 85 \\
\hline Total Geral & $\mathbf{1 1 3}$ & $\mathbf{8 9}$ & $\mathbf{3 2}$ & $\mathbf{2 3 4}$ \\
\hline
\end{tabular}

\section{RESULTADOS}

Na primeira parte dos resultados apresenta-se a estrutura e funcionamento do site para conhecimento. A segunda parte dos resultados foi estruturada conforme os objetivos específicos estabelecidos na pesquisa: a) apresentar dados quantitativos sobre a evolução do uso do site ao longo dos meses desde julho de 2010 até junho de 2012; b) apresentar o fluxo de acessos dos usuários no site; c) apontar a avaliação dos professores e alunos usuários do site.

\subsection{Estrutura e funcionamento do site}

O site do departamento utilizou o sistema Google Sites® disponível para a UNEMAT. O sistema é gratuito e não tem limite de espaço para a Universidade. Esse sistema permite a criação de sites diretamente pelo navegador, sem necessidade de instalação de softwares específicos para criação de sites. $O$ endereço original do site é https://sites.google.com/a/unemat.br/cictga, contudo, para facilitar o acesso e memorização do endereço foram criados dois atalhos no servidor da UNEMAT que redirecionam para este endereço. Os atalhos ficam nos endereços: http://tangara.unemat.br/contabeis e http://www2.unemat.br/contabeistga. O primeiro endereço é na página do campus de Tangará da Serra o segundo no servidor da Universidade. O sistema foi escolhido pelo departamento porque: 1) é grátis; 2) é fácil para os usuários; 3) pode ser acessado e alterado em qualquer computador pelos usuários que tenham acesso. 


\section{AVALIAÇÃO DO USO DE SITE PARA INTERAÇÃO CURSO X PROFESSOR X ALUNO: CASO DO CURSO DE CIÊNCIAS CONTÁBEIS DA UNEMAT - CAMPUS DE TANGARÁ DA SERRA \\ Laércio Juarez Melz Cleiton Franco \\ Karine Medeiros Anunciato \\ Eugênio Carlos Stieler \\ Adielson Gonçalves de Lima}

A aparência do site é estruturada em dois menus e uma área informativa central (Figura 1). O menu da esquerda inclui as opções detalhadas, com acesso à páginas específicas do site. Percebe-se que é esperado maior acesso a esse menu, pois, ele detalha opções que serão utilizadas pelos alunos e professores. $\mathrm{O}$ menu superior exibe acesso à páginas com informações mais gerais, destinadas ao público não vinculado ao curso. $\mathrm{Na}$ área informativa central percebe-se que há as informações sobre contato e horário de atendimento. Também são apresentados 3 quadros. O primeiro quadro contém os avisos de professores para os alunos e o segundo os avisos do departamento para os alunos. O terceiro quadro demonstra as substituições de aulas programadas pelos professores ou pelo departamento.

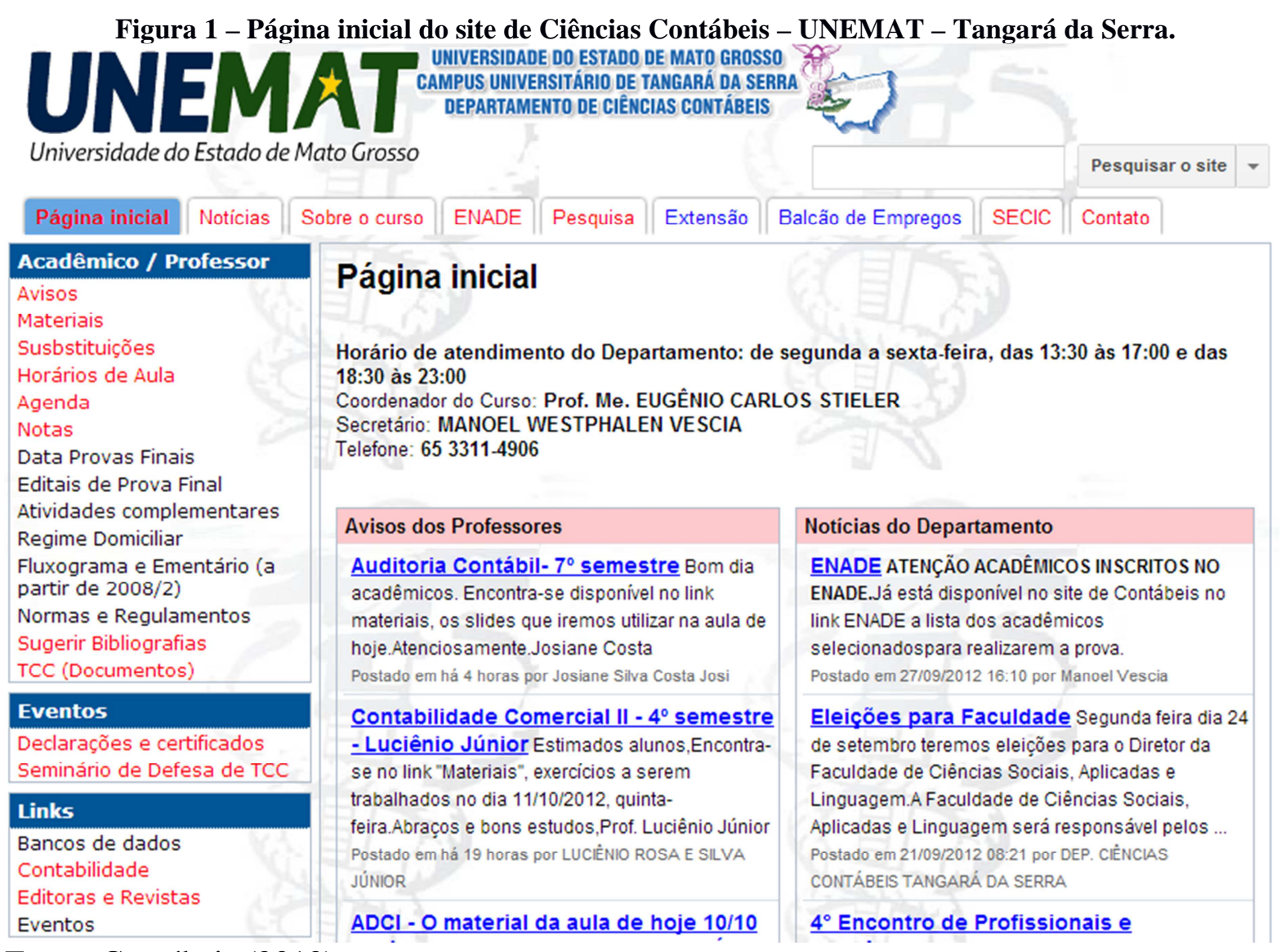

Fonte: Contábeis (2012).

As páginas do site estão organizadas em estrutura de páginas e subpáginas. Cada pode conter quantas subpáginas forem necessárias. Essa estrutura organiza os conteúdos dentro de algumas pastas principais. A pasta "Acadêmico" inclui os conteúdos que os alunos e professores têm acesso, como: materiais, substituições, horários, avisos, editais de provas Revista UNEMAT de Contabilidade 


\section{AVALIAÇÃO DO USO DE SITE PARA INTERAÇÃO CURSO X PROFESSOR X ALUNO: CASO DO CURSO DE CIÊNCIAS CONTÁBEIS DA UNEMAT - CAMPUS DE TANGARÁ DA SERRA \\ Laércio Juarez Melz Cleiton Franco \\ Karine Medeiros Anunciato \\ Eugênio Carlos Stieler \\ Adielson Gonçalves de Lima}

finais, notas, planos de ensino e outros. Esses conteúdos são de livre atualização pelos professores. Percebe-se que são conteúdos direcionados especificamente para os alunos. A pasta "Sobre o curso" contém informações sobre o curso, tais como: colegiado de curso, docentes lotados, fluxo discente, matriz curricular entre outros. Percebe-se que esta pasta é destinada aos usuários que desejam conhecer o funcionamento do curso. Outras páginas contém informações úteis tanto para os professores e alunos, quanto para usuários não vinculados ao curso, são: links, pesquisa, páginas informativas, eventos e comunidade (Quadro 2).

Quadro 2 - Páginas e subpáginas do site de Ciências Contábeis - UNEMAT - Tangará da Serra.

\begin{tabular}{|c|c|c|c|c|c|c|}
\hline Acadêmico & Sobre o curso & Links & Pesquisa & $\begin{array}{c}\text { Páginas } \\
\text { informativas }\end{array}$ & Eventos & Comunidade \\
\hline Agenda & $\begin{array}{l}\text { Colegiado de } \\
\text { Curso }\end{array}$ & Bancos de dados & $\begin{array}{c}\text { Linhas de } \\
\text { Pesquisa }\end{array}$ & Página inicial & $\begin{array}{c}\text { Declarações e } \\
\text { certificados }\end{array}$ & $\begin{array}{l}\text { Balcão de } \\
\text { Empregos }\end{array}$ \\
\hline $\begin{array}{c}\text { Atividades } \\
\text { complementares }\end{array}$ & Docentes lotados & Contabilidade & $\begin{array}{c}\text { Projetos de } \\
\text { Pesquisa }\end{array}$ & Contato & $\begin{array}{c}\text { Seminário de } \\
\text { Defesa de TCC }\end{array}$ & \\
\hline Avisos & Fluxo Discente & $\begin{array}{c}\text { Editoras e } \\
\text { Revistas }\end{array}$ & Publicações & Notícias & & \\
\hline Declarações & $\begin{array}{c}\text { Fluxograma e } \\
\text { Ementário (a } \\
\text { partir de 2008/2) }\end{array}$ & Eventos & Tabela de áreas & Extensão & & \\
\hline $\begin{array}{c}\text { Editais de Prova } \\
\text { Final }\end{array}$ & Histórico & & & & & \\
\hline ENADE & Matriz Curricular & & & & & \\
\hline Horários de Aula & $\begin{array}{c}\text { Normas e } \\
\text { Regulamentos }\end{array}$ & & & & & \\
\hline Materiais & $\begin{array}{l}\text { Núcleo Docente } \\
\text { Estruturante } \\
\text { (NDE) }\end{array}$ & & & & & \\
\hline Notas & $\begin{array}{c}\text { Parceiros do } \\
\text { departamento }\end{array}$ & & & & & \\
\hline $\begin{array}{c}\text { Planos de ensino } \\
\text { (Ementa) }\end{array}$ & $\begin{array}{c}\text { Sugerir } \\
\text { Bibliografias } \\
\end{array}$ & & & & & \\
\hline $\begin{array}{c}\text { Regime } \\
\text { Domiciliar }\end{array}$ & & & & & & \\
\hline Susbstituições & & & & & & \\
\hline $\begin{array}{c}\text { TCC } \\
\text { (Documentos) }\end{array}$ & & & & & & \\
\hline
\end{tabular}

Fonte: Contábeis (2012), elaborado pelos autores.

Os professores e o departamento têm acesso ao site via navegador. Para acessar o site professor deve possuir um e-mail da Universidade ou do Gmail®, pertencente ao Google. Esse e-mail garante o acesso às alterações do site. O funcionamento é do tipo "what you see is what you get', em tradução livre 'o que é visto é a versão final', isso garante que o professor visualize a página tal como ela será exibida ao usuário. Esse recurso tem sido utilizado para facilitar a montagem de páginas web e websites. 


\section{AVALIAÇÃO DO USO DE SITE PARA INTERAÇÃO CURSO X PROFESSOR X ALUNO: CASO DO CURSO DE CIÊNCIAS CONTÁBEIS DA UNEMAT - CAMPUS DE TANGARÁ DA SERRA \\ Laércio Juarez Melz Cleiton Franco \\ Karine Medeiros Anunciato \\ Eugênio Carlos Stieler \\ Adielson Gonçalves de Lima}

\subsection{Dados sobre acesso e permanência no site}

Por meio da importação dos dados de acesso foi possível identificar que o número de visitas tem aumentado ao longo dos meses. Número de visitas reflete o a quantidade de acessos ao site. Neste caso não se diferencia os usuários, um usuário pode realizar mais que uma visita ao site. Entre julho de 2010 e junho de 2012 foram registradas 117.270 visitas. Em média, no ano de 2010 foram 5.699 visitas ao site. Em 2011 foram 4.686 visitas e em 2012 foram 4.368 (Tabela 3).

Em julho de 2010 o número de visitas é reduzido, pois, foi o segundo mês de controle de visitantes no site. Os meses com maior número de visitas foram, em 2010, dezembro e novembro. Em 2011, os meses de março e setembro tiveram o maior número de visitas. Em 2012, o mês de junho teve o maior número de visitas. Percebeu-se que no mês de janeiro, em 2011 e 2012, houve o menor número de visitas, movimento esperado por conta das férias de verão. Entre julho de 2010 e junho de 2012 o crescimento de acessos foi de $61 \%$ (Tabela 3).

Tabela 3 - Número de visitas por mês, jul-2010 a jun-2012.

\begin{tabular}{c|c|c|c|c|c|c|c|c}
\hline Meses & $\mathbf{2 0 1 0}$ & $\mathbf{2 0 1 1}$ & $\mathbf{2 0 1 2}$ & Total Mês & Média Mensal & \% 2010 & \% 2011 & \% 2012 \\
\hline Jan & & 2.063 & 1.386 & 3.449 & 1.725 & & $-43 \%$ & $-62 \%$ \\
\hline Fev & & 5.268 & 4.365 & 9.633 & 4.817 & & $45 \%$ & $20 \%$ \\
\hline Mar & & 6.553 & 4.764 & 11.317 & 5.659 & & $81 \%$ & $31 \%$ \\
\hline Abr & & 4.333 & 4.349 & 8.682 & 4.341 & & $19 \%$ & $20 \%$ \\
\hline Mai & & 4.469 & 5.510 & 9.979 & 4.990 & & $23 \%$ & $52 \%$ \\
\hline Jun & & 5.643 & 5.834 & 12.117 & 5.739 & & $56 \%$ & $61 \%$ \\
\hline Jul & 3.627 & 3.908 & & 7.535 & 3.768 & & $8 \%$ & \\
\hline Ago & 5.194 & 4.817 & & 10.011 & 5.006 & $43 \%$ & $33 \%$ & \\
\hline Set & 5.779 & 6.289 & & 12.068 & 6.034 & $59 \%$ & $73 \%$ & \\
\hline Out & 5.188 & 4.226 & & 9.414 & 4.707 & $43 \%$ & $17 \%$ & \\
\hline Nov & 7.061 & 4.077 & & 11.138 & 5.569 & $95 \%$ & $12 \%$ & \\
\hline Dez & 7.342 & 4.585 & & 11.927 & 5.964 & $102 \%$ & $26 \%$ & \\
\hline Total Ano & $\mathbf{3 4 . 8 3 1}$ & $\mathbf{5 6 . 2 3 1}$ & $\mathbf{2 6 . 2 0 8}$ & $\mathbf{1 1 7 . 2 7 0}$ & & & & \\
\hline Média Ano & 5.699 & 4.686 & 4.368 & & & & & \\
\hline
\end{tabular}

Fonte: Dados obtidos pelo Google Analytics®, organizados pelos autores.

O número de visitantes reflete os acessos ao site por endereço de Internet Protocol (IP) do computador. Considera-se cada IP como um usuário único, pois, o número não se repete na rede. Esse controle é diário, portanto, um usuário pode acessar com o mesmo IP em vários dias, para cada dia ele será contado como um usuário único. No período analisado, jul/2010 a jun/2012, totalizaram 85.255 visitantes únicos. A média de visitantes em 2010 foi 


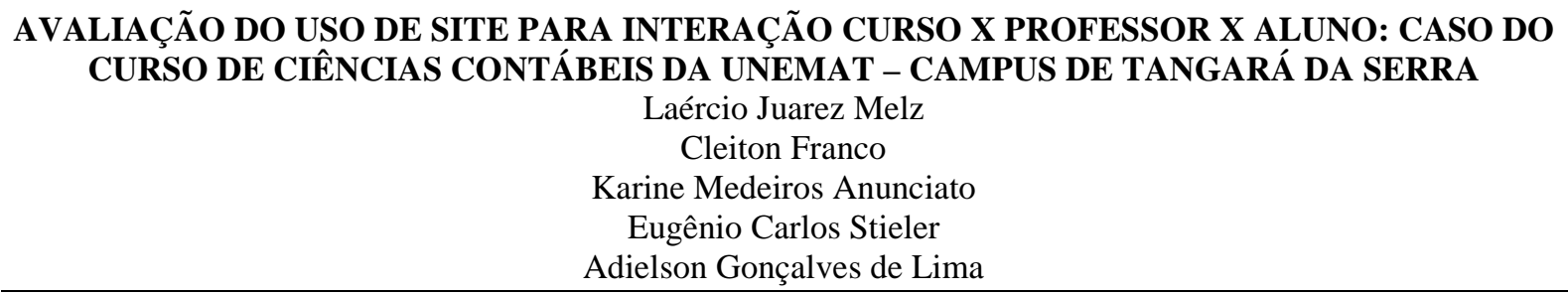

de 3.993 por mês. Em 2011 foram, em média mensal, 3.460 visitantes e em 2012, até junho foram 3.209 ao mês (Tabela 4).

Os meses com maior número de visitantes foram novembro e dezembro de 2010, março e setembro de 2011. Em 2012, percebeu-se redução do número de visitantes únicos. O maior aumento de número de usuários em relação ao primeiro mês de controle, jul/2010, foi registrado em março de 2011, 38\% mais usuários. No mês de janeiro acontece a redução do número de usuários do site, chegando a queda de $66 \%$ em janeiro de 2012 . No mês de julho também registra-se queda no número de usuários (Tabela 4). Ambos os meses refletem as férias dos alunos, portanto, pode-se perceber que são os alunos quem mais acessam o site.

Tabela 4 - Número de visitantes únicos por mês, jul/2010 a jun/2012.

\begin{tabular}{c|c|c|c|c|c|c|c|c}
\hline Meses & $\mathbf{2 0 1 0}$ & $\mathbf{2 0 1 1}$ & $\mathbf{2 0 1 2}$ & Total Mês & Média Mensal & $\mathbf{2 0 1 0}$ & $\mathbf{2 0 1 1}$ & $\mathbf{2 0 1 2}$ \\
\hline Jan & & 1.777 & 1.247 & 3.024 & 1.512 & & $-51 \%$ & $-66 \%$ \\
\hline Fev & & 4.018 & 3.384 & 7.402 & 3.701 & & $11 \%$ & $-7 \%$ \\
\hline Mar & & 5.016 & 3.632 & 8.648 & 4.324 & & $38 \%$ & $0 \%$ \\
\hline Abr & & 3.245 & 3.286 & 6.531 & 3.266 & & $-11 \%$ & $-9 \%$ \\
\hline Mai & & 3.356 & 3.914 & 7.270 & 3.635 & & $-7 \%$ & $8 \%$ \\
\hline Jun & & 3.771 & 3.790 & 8.081 & 3.781 & & $4 \%$ & $4 \%$ \\
\hline Jul & 2.411 & 2.774 & & 5.185 & 2.593 & & $-24 \%$ & \\
\hline Ago & 3.880 & 3.676 & & 7.556 & 3.778 & $7 \%$ & $1 \%$ & \\
\hline Set & 4.170 & 4.551 & & 8.721 & 4.361 & $15 \%$ & $25 \%$ & \\
\hline Out & 3.854 & 3.125 & & 6.979 & 3.490 & $6 \%$ & $-14 \%$ & \\
\hline Nov & 4.939 & 3.094 & & 8.033 & 4.017 & $36 \%$ & $-15 \%$ & \\
\hline Dez & 4.705 & 3.120 & & 7.825 & 3.913 & $30 \%$ & $-14 \%$ & \\
\hline Total Ano & $\mathbf{2 4 . 4 7 9}$ & $\mathbf{4 1 . 5 2 3}$ & $\mathbf{1 9 . 2 5 3}$ & $\mathbf{8 5 . 2 5 5}$ & & & & \\
\hline Média Ano & 3.993 & 3.460 & 3.209 & & & & & \\
\hline Fonte: Dad & & & & & \\
\end{tabular}

Fonte: Dados obtidos pelo Google Analytics ${ }^{\circledR}$, organizados pelos autores.

O número de visualizações de páginas tem diminuído ao longo do período analisado. Visualização de páginas significa acesso a cada página do site. A média de visualizações (page views) foi de 22.853, em 2010, passando para 13.891, em 2012. O motivo provável é que os alunos já adquiriram a experiência com o site, já exploraram todas as páginas e, portanto, passam a ser mais objetivos, seguindo diretamente para as páginas desejadas. Todavia o tempo médio de permanência em cada página tem aumentado. Em 2010, os visitantes permaneciam, em média, 3 minutos em cada página. Em 2012 esse tempo aumentou para 4 minutos.

Tabela 5 - Número de visualizações de páginas e tempo médio por página, jul/2010 a jun/2012.

\begin{tabular}{c|c|c|c|c|c|c|c|c|c}
\hline Meses & $\mathbf{2 0 1 0}$ & $\mathbf{2 0 1 1}$ & $\mathbf{2 0 1 2}$ & Total Mês & Média Mês & $\mathbf{2 0 1 0}$ & $\mathbf{2 0 1 1}$ & $\mathbf{2 0 1 2}$ & Média \\
\hline
\end{tabular}




\begin{tabular}{|c|c|c|c|c|c|c|c|c|c|}
\hline $\begin{array}{l}\text { VALIAC } \\
\text { CURS }\end{array}$ & $\begin{array}{l}\text { D DO I } \\
\text { DE C }\end{array}$ & $\begin{array}{l}\text { D DE S } \\
\text { JCIAS }\end{array}$ & $\begin{array}{l}\text { PARA } \\
\text { NTÁB }\end{array}$ & $\begin{array}{l}\text { INTERA } \\
\text { IS DA UN } \\
\text { Laércio } \\
\text { Cleito } \\
\text { rine Med } \\
\text { Eugênio } \\
\text { ielson Go }\end{array}$ & $\begin{array}{l}\text { O CURS } \\
\text { IAT - C } \\
\text { ez Melz } \\
\text { ranco } \\
\text { s Anuncia } \\
\text { os Stieler } \\
\text { lves de Li }\end{array}$ & MPUS DE & TANGAR & Á DA SE & RA \\
\hline Jan & & 6.071 & 3.169 & 9.240 & 4.620 & & $00: 02: 38$ & $00: 01: 52$ & 00:02:15 \\
\hline $\mathrm{Fev}$ & & 21.258 & 15.274 & 36.532 & 18.266 & & 00:03:45 & 00:04:22 & 00:04:04 \\
\hline Mar & & 24.864 & 14.656 & 39.520 & 19.760 & & $00: 03: 26$ & \begin{tabular}{|l|}
$00: 04: 15$ \\
\end{tabular} & 00:03:51 \\
\hline Abr & & 15.164 & 13.774 & 28.938 & 14.469 & & 00:03:19 & \begin{tabular}{|l|}
$00: 03: 58$ \\
\end{tabular} & 00:03:39 \\
\hline Mai & & 14.143 & 16.732 & 30.875 & 15.438 & & $00: 03: 21$ & \begin{tabular}{|l|}
$00: 04: 38$ \\
\end{tabular} & \begin{tabular}{|l|}
$00: 03: 59$ \\
\end{tabular} \\
\hline Jun & & 19.332 & 19.739 & 39.071 & 19.536 & & 00:03:51 & \begin{tabular}{|l|}
$00: 04: 52$ \\
\end{tabular} & 00:03:21 \\
\hline Jul & 13.151 & 12.156 & & 25.307 & 12.654 & $00: 02: 55$ & 00:03:26 & & 00:03:11 \\
\hline Ago & 25.501 & 15.206 & & 40.707 & 20.354 & 00:04:05 & \begin{tabular}{|l|}
$00: 03: 48$ \\
\end{tabular} & & $00: 03: 56$ \\
\hline Set & 24.624 & 20.310 & & 44.934 & 22.467 & 00:03:27 & \begin{tabular}{|l|}
$00: 05: 49$ \\
\end{tabular} & & 00:04:38 \\
\hline Out & 18.675 & 11.954 & & 30.629 & 15.315 & 00:03:01 & 00:04:06 & & 00:03:34 \\
\hline Nov & 25.414 & 12.158 & & 37.572 & 18.786 & 00:03:38 & \begin{tabular}{|l|}
$00: 03: 41$ \\
\end{tabular} & & 00:03:39 \\
\hline Dez & 29.751 & 15.451 & & 45.202 & 22.601 & 00:03:06 & \begin{tabular}{|l|}
$00: 04: 01$ \\
\end{tabular} & & 00:03:34 \\
\hline Total Ano & 137.116 & 188.067 & 83.344 & 408.527 & & 00:03:22 & \begin{tabular}{|l|}
$00: 03: 46$ \\
\end{tabular} & \begin{tabular}{|l|}
$00: 04: 00$ \\
\end{tabular} & \begin{tabular}{|l|}
$00: 03: 38$ \\
\end{tabular} \\
\hline Média Ano & 22.853 & 15.672 & 13.891 & 34.044 & & & & & \\
\hline
\end{tabular}

Fonte: Dados obtidos pelo Google Analytics®, organizados pelos autores.

\subsection{Dados sobre movimentação dos usuários pelo site}

Analisando os dados sobre média de páginas vistas por visita e por visitante entre jul/2010 e jun/2012, percebe-se que houve decréscimo nesse número. A média era de 3,89 páginas por visita e 5,30 por visitante, em 2010. Em 2012 essa média caiu para 3,02 por visita e 3,95 por visitante. O maior número de páginas por visita e por visitante aconteceu em agosto e setembro de 2010, quando o site era novidade. Isso significa que os usuários têm focado em algumas páginas e não têm explorado as demais páginas do site (Tabela 6).

Tabela 6 - Média de páginas visitadas por acesso e visitantes, jul/2010 a jun/2012.

\begin{tabular}{c|c|c|c|c|c|c|c|c}
\hline Meses & $\mathbf{2 0 1 0}$ & $\mathbf{2 0 1 1}$ & $\mathbf{2 0 1 2}$ & Média & $\mathbf{2 0 1 0}$ & $\mathbf{2 0 1 1}$ & $\mathbf{2 0 1 2}$ & Média \\
\hline Jan & & 2,94 & 2,25 & 2,59 & & 3,38 & 2,47 & 2,93 \\
\hline Fev & & 3,73 & 3,42 & 3,57 & & 4,77 & 4,26 & 4,52 \\
\hline Mar & & 3,88 & 3,13 & 3,50 & & 4,94 & 3,98 & 4,46 \\
\hline Abr & & 3,51 & 3,19 & 3,35 & & 4,53 & 4,19 & 4,36 \\
\hline Mai & & 3,15 & 3,01 & 3,08 & & 4,13 & 4,15 & 4,14 \\
\hline Jun & & 3,35 & 3,15 & 3,25 & & 4,90 & 4,65 & 4,78 \\
\hline Jul & 3,42 & 2,90 & & 3,16 & 4,84 & 3,88 & & 4,36 \\
\hline Ago & 4,79 & 3,05 & & 3,92 & 6,19 & 3,96 & & 5,08 \\
\hline Set & 4,31 & 3,20 & & 3,75 & 5,80 & 4,28 & & 5,04 \\
\hline Out & 3,56 & 2,80 & & 3,18 & 4,68 & 3,68 & & 4,18 \\
\hline Nov & 3,57 & 2,98 & & 3,27 & 4,96 & 3,81 & & 4,38 \\
\hline Dez & 3,69 & 3,01 & & 3,35 & 5,36 & 4,14 & & 4,75 \\
\hline Média & $\mathbf{3 , 8 9}$ & $\mathbf{3 , 2 1}$ & $\mathbf{3 , 0 2}$ & $\mathbf{3 , 3 3}$ & $\mathbf{5 , 3 0}$ & $\mathbf{4 , 2 0}$ & $\mathbf{3 , 9 5}$ & $\mathbf{4 , 4 1}$ \\
\hline
\end{tabular}

Fonte: Dados obtidos pelo Google Analytics®, organizados pelos autores.

No período analisado o site teve as visitas em sua grande maioria originadas de computadores com sistema Windows ${ }^{\circledR}$. Aproximadamente 112 mil visitantes acessaram pelo 
AVALIAÇÃO DO USO DE SITE PARA INTERAÇÃO CURSO X PROFESSOR X ALUNO: CASO DO

CURSO DE CIÊNCIAS CONTÁBEIS DA UNEMAT - CAMPUS DE TANGARÁ DA SERRA

Laércio Juarez Melz

Cleiton Franco

Karine Medeiros Anunciato

Eugênio Carlos Stieler

Adielson Gonçalves de Lima

sistema, 95\% do total de visitas. Visitas utilizando o Linux, sistema livre, representaram somente 3\% dos acessos. Foram registrados também 657 acessos via celulares com sistemas Android ou Symbian OS. Isso demonstra que ainda há pouca difusão do sistema Linux entre os usuários do site e o acesso via celular é ínfimo (Figura 2).

A maioria dos acessos ao site parte da página inicial, aproximadamente 76 mil visitas tiveram como ponto de partida a página inicial, $64 \%$ do total de visitas. Partindo da página inicial, a maioria dos usuários seguem, em primeira interação, para a página de materiais dos professores, aproximadamente 21 mil visitas. A página de avisos recebeu 14 mil visitas e a de notas recebeu 10 mil visitas, na primeira interação dos usuários no site (Figura 2). Como segunda interação, os usuários que costumam passar pela primeira interação pelas páginas de materiais, seguem para páginas não listadas na figura. Os usuários que, em sua primeira interação acessam os avisos, seguem para a página de materiais ou para a página inicial do site (Figura 2).

Figura 2 - Interações dos usuários a partir do sistema operacional de origem, em milhares, entre jul-2010

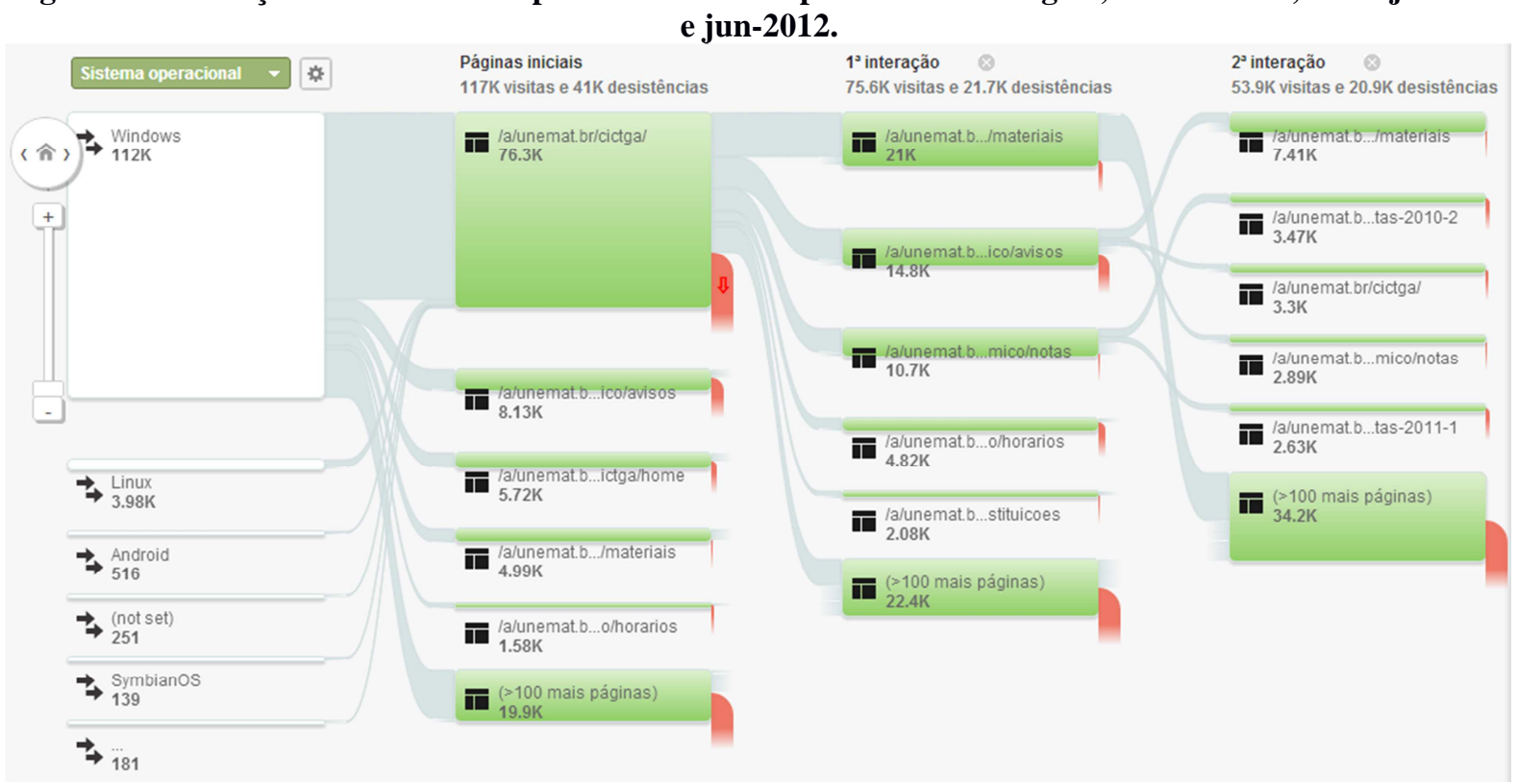

Fonte: Google Analytics (2012).

\subsection{Avaliação dos usuários}

As avaliações foram realizadas considerando o vínculo dos respondentes com o departamento. Os percentuais são sempre em relação ao total de respostas, 234. O primeiro quesito avaliado foi: simplicidade e clareza. Percebeu-se que, em todos os tipos de vínculos, a 


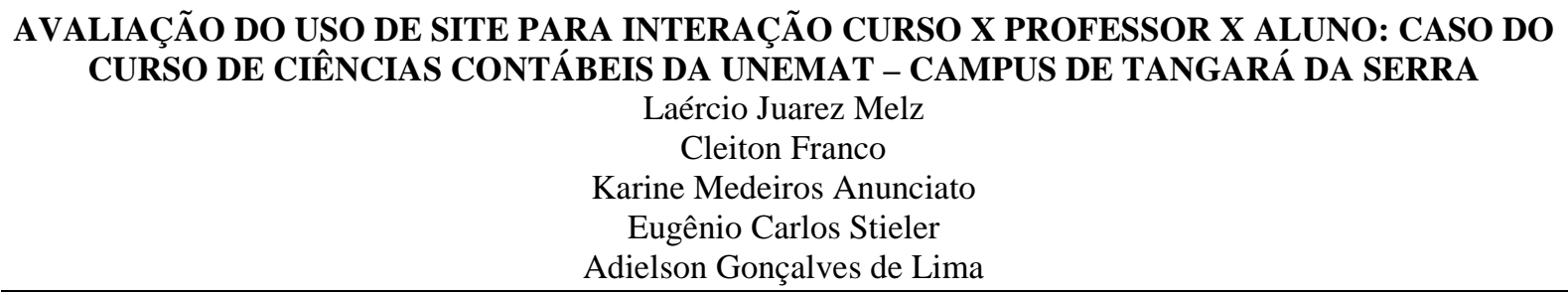

maioria das respostas foi entre bom e ótimo. Pode-se afirmar, então, que o site é simples e claro a $65,81 \%$ dos respondentes (Tabela 7 ).

Tabela 7 - Avaliação do site em relação à simplicidade e clareza, em \% do total de respostas.

\begin{tabular}{c|c|c|c|c}
\hline Avaliação & Acadêmico & Professor & Não possui vínculo & Total Avaliação \\
\hline Péssimo & $6,41 \%$ & $0,43 \%$ & $0,43 \%$ & $7,26 \%$ \\
\hline Ruim & $5,13 \%$ & $0,00 \%$ & $1,28 \%$ & $6,41 \%$ \\
\hline Regular & $18,80 \%$ & $0,00 \%$ & $1,71 \%$ & $20,51 \%$ \\
\hline Bom & $29,49 \%$ & $1,28 \%$ & $2,99 \%$ & $33,76 \%$ \\
\hline Ótimo & $26,50 \%$ & $2,14 \%$ & $3,42 \%$ & $32,05 \%$ \\
\hline Total Vínculo & $\mathbf{8 6 , 3 2 \%}$ & $\mathbf{3 , 8 5 \%}$ & $\mathbf{9 , 8 3 \%}$ & $\mathbf{1 0 0 , 0 0 \%}$ \\
\hline
\end{tabular}

Em relação à organização dos conteúdos o site, a avaliação do site também foi positiva. Do total de respostas $61,11 \%$ foram classificados como bom ou ótimo. Ressalte-se que, entre os acadêmicos, houve $20 \%$ de respostas iguais a regular (Tabela 8).

Tabela 8 - Avaliação do site em relação à organização dos conteúdos, em \% do total de respostas.

\begin{tabular}{c|c|c|c|c}
\hline Avaliação & Acadêmico & Professor & Não possui vínculo & Total Avaliação \\
\hline Péssimo & $9,40 \%$ & $0,00 \%$ & $0,85 \%$ & $10,26 \%$ \\
\hline Ruim & $5,56 \%$ & $0,43 \%$ & $1,28 \%$ & $7,26 \%$ \\
\hline Regular & $20,51 \%$ & $0,00 \%$ & $0,85 \%$ & $21,37 \%$ \\
\hline Bom & $26,07 \%$ & $0,85 \%$ & $4,27 \%$ & $31,20 \%$ \\
\hline Ótimo & $24,79 \%$ & $2,56 \%$ & $2,56 \%$ & $29,91 \%$ \\
\hline Total Vínculo & $\mathbf{8 6 , 3 2 \%}$ & $\mathbf{3 , 8 5 \%}$ & $\mathbf{9 , 8 3 \%}$ & $\mathbf{1 0 0 , 0 0 \%}$ \\
\hline
\end{tabular}

Em relação à aparência do site foi avaliada como boa ou ótima por 46,58\% dos respondentes. Percebe-se que, entre os acadêmicos, ainda há possibilidade de melhoria na aparência, pois, $23,93 \%$ avaliaram como regular. Influenciando também o computo de $26,5 \%$ do total de respostas 'regular'. Entre os professores não há opinião formada, os resultados foram muito próximos em cada avaliação.

Tabela 9 - Avaliação do site em relação à aparência, em \% do total de respostas.

\begin{tabular}{c|c|c|c|c}
\hline Avaliação & Acadêmico & Professor & Não possui vínculo & Total Avaliação \\
\hline Péssimo & $13,25 \%$ & $0,43 \%$ & $0,85 \%$ & $14,53 \%$ \\
\hline Ruim & $9,83 \%$ & $0,43 \%$ & $2,14 \%$ & $12,39 \%$ \\
\hline Regular & $23,93 \%$ & $0,43 \%$ & $2,14 \%$ & $26,50 \%$ \\
\hline Bom & $18,38 \%$ & $0,85 \%$ & $2,14 \%$ & $21,37 \%$ \\
\hline Ótimo & $20,94 \%$ & $1,71 \%$ & $2,56 \%$ & $25,21 \%$ \\
\hline Total Vínculo & $\mathbf{8 6 , 3 2 \%}$ & $\mathbf{3 , 8 5 \%}$ & $\mathbf{9 , 8 3 \%}$ & $\mathbf{1 0 0 , 0 0 \%}$ \\
\hline
\end{tabular}




\section{AVALIAÇÃO DO USO DE SITE PARA INTERAÇÃO CURSO X PROFESSOR X ALUNO: CASO DO CURSO DE CIÊNCIAS CONTÁBEIS DA UNEMAT - CAMPUS DE TANGARÁ DA SERRA \\ Laércio Juarez Melz Cleiton Franco \\ Karine Medeiros Anunciato \\ Eugênio Carlos Stieler \\ Adielson Gonçalves de Lima}

Com relação à divulgação das ações do Departamento, 57,27\% avaliaram como bom ou ótimo e 24,36\% avaliaram como regular (Tabela 10). Indicativo de que ainda há necessidade de melhoria na divulgação das ações do departamento.

Tabela 10 - Avaliação do site em relação à divulgação de ações do Departamento, em \% do total de

\begin{tabular}{c|c|c|c|c}
\hline \multicolumn{5}{|c}{ respostas. } \\
\hline Avaliação & Acadêmico & Professor & Não possui vínculo & Total Avaliação \\
\hline Péssimo & $9,40 \%$ & $0,43 \%$ & $0,43 \%$ & $10,26 \%$ \\
\hline Ruim & $7,26 \%$ & $0,00 \%$ & $0,85 \%$ & $8,12 \%$ \\
\hline Regular & $21,37 \%$ & $0,00 \%$ & $2,99 \%$ & $24,36 \%$ \\
\hline Bom & $25,21 \%$ & $1,71 \%$ & $3,85 \%$ & $30,77 \%$ \\
\hline Ótimo & $23,08 \%$ & $1,71 \%$ & $1,71 \%$ & $26,50 \%$ \\
\hline Total Vínculo & $\mathbf{8 6 , 3 2 \%}$ & $\mathbf{3 , 8 5 \%}$ & $\mathbf{9 , 8 3 \%}$ & $\mathbf{1 0 0 , 0 0 \%}$ \\
\hline
\end{tabular}

Uma das principais funcionalidades do site, em seu projeto, seria a postagem de materiais pelos professores. Historicamente os professores deixavam apostilas na fotocopiadora ou mandavam para um e-mail da turma. A fotocópia tem custo para os acadêmicos e o e-mail sofria 'acidentes de percurso', quando alguém apagava o material. A postagem de materiais surgiu como solução para esses dois problemas. A avaliação da disponibilidade de materiais, apesar de 27,35\% dos respondentes terem apontando como regular, somando-se avaliações positivas 52,99\% (bom+ótimo) (Tabela 11). Todavia é necessário observar que $24,36 \%$ dos acadêmicos avaliaram como regular. Isso é um dado importante porque a finalidade da postagem de materiais é justamente atender ao acadêmico. Pode ser que os professores não usem o recurso tal como deveriam.

Tabela 11 - Avaliação do site em relação à disponibilidade de materiais, em \% do total de respostas.

\begin{tabular}{c|c|c|c|c}
\hline Avaliação & Acadêmico & Professor & Não possui vínculo & Total Avaliação \\
\hline Péssimo & $8,55 \%$ & $0,00 \%$ & $0,43 \%$ & $8,97 \%$ \\
\hline Ruim & $9,40 \%$ & $0,43 \%$ & $0,85 \%$ & $10,68 \%$ \\
\hline Regular & $24,36 \%$ & $0,00 \%$ & $2,99 \%$ & $27,35 \%$ \\
\hline Bom & $21,79 \%$ & $1,71 \%$ & $3,42 \%$ & $26,92 \%$ \\
\hline Ótimo & $22,22 \%$ & $1,71 \%$ & $2,14 \%$ & $26,07 \%$ \\
\hline Total Vínculo & $\mathbf{8 6 , 3 2 \%}$ & $\mathbf{3 , 8 5 \%}$ & $\mathbf{9 , 8 3 \%}$ & $\mathbf{1 0 0 , 0 0 \%}$ \\
\hline
\end{tabular}

O ponto fraco detectado no site é o link "Balcão de Empregos". O link foi projetado com o objetivo de levar ao encontro as empresas que precisavam de acadêmicos e os acadêmicos que precisavam de emprego. Contudo, pouco ou nada foi utilizado no período analisado. Como seria de esperar, a avaliação apresentou-se como ruim ou péssima por 


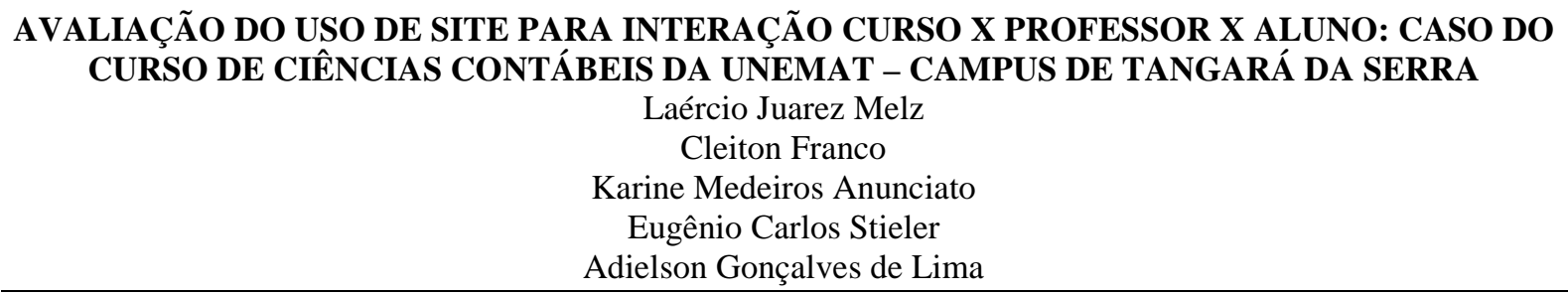

$35,9 \%$ dos respondentes, 32,91\% das respostas negativas vindas de acadêmicos. Apesar disso, 39,74\% avaliaram como bom ou ótimo (Tabela 12).

Tabela 12 - Avaliação do site em relação à disponibilidade de materiais, em \% do total de respostas.

\begin{tabular}{c|c|c|c|c}
\hline Avaliação & Acadêmico & Professor & Não possui vínculo & Total Avaliação \\
\hline Péssimo & $18,38 \%$ & $0,43 \%$ & $0,43 \%$ & $19,23 \%$ \\
\hline Ruim & $14,53 \%$ & $0,43 \%$ & $1,71 \%$ & $16,67 \%$ \\
\hline Regular & $20,51 \%$ & $0,00 \%$ & $3,85 \%$ & $24,36 \%$ \\
\hline Bom & $21,37 \%$ & $2,14 \%$ & $2,56 \%$ & $26,07 \%$ \\
\hline Ótimo & $11,54 \%$ & $0,85 \%$ & $1,28 \%$ & $13,68 \%$ \\
\hline Total Vínculo & $\mathbf{8 6 , 3 2 \%}$ & $\mathbf{3 , 8 5 \%}$ & $\mathbf{9 , 8 3 \%}$ & $\mathbf{1 0 0 , 0 0 \%}$ \\
\hline
\end{tabular}

O site também incluiu página para publicações de professores e acadêmicos. A avaliação desta parte do site foi de 50,85\% de bom ou ótimo. Houve também 27,78\% que avaliaram como regular. Entre os acadêmicos e não vinculados houve maioria de avaliações regulares (Tabela 13). Isso indica que ainda há o que melhorar neste quesito no site.

Tabela 13 - Avaliação do site em relação à publicações, em \% do total de respostas.

\begin{tabular}{c|c|c|c|c}
\hline Avaliação & Acadêmico & Professor & Não possui vínculo & Total Avaliação \\
\hline Péssimo & $8,12 \%$ & $0,43 \%$ & $0,85 \%$ & $9,40 \%$ \\
\hline Ruim & $10,68 \%$ & $0,00 \%$ & $1,28 \%$ & $11,97 \%$ \\
\hline Regular & $23,93 \%$ & $0,85 \%$ & $2,99 \%$ & $27,78 \%$ \\
\hline Bom & $25,21 \%$ & $0,85 \%$ & $2,56 \%$ & $28,63 \%$ \\
\hline Ótimo & $18,38 \%$ & $1,71 \%$ & $2,14 \%$ & $22,22 \%$ \\
\hline Total Vínculo & $\mathbf{8 6 , 3 2 \%}$ & $\mathbf{3 , 8 5 \%}$ & $\mathbf{9 , 8 3 \%}$ & $\mathbf{1 0 0 , 0 0 \%}$ \\
\hline
\end{tabular}

Outro quesito avaliado foram as informações sobre o curso. Para usuários não vinculados são importantes informações para conhecer melhor o curso. O quesito foi bem avaliado em todos os segmentos. 58,12\% dos respondentes avaliaram como bom ou ótimo. Sedo ótimo apontado com maior frequência de respostas, 31,20\%. Isso demonstra que este objetivo tem sido atingido pelo site.

Tabela 14 - Avaliação do site em relação à informações sobre o curso, em \% do total de respostas.

\begin{tabular}{c|c|c|c|c}
\hline Avaliação & Acadêmico & Professor & Não possui vínculo & Total Avaliação \\
\hline Péssimo & $9,83 \%$ & $0,43 \%$ & $0,43 \%$ & $10,68 \%$ \\
\hline Ruim & $6,84 \%$ & $0,00 \%$ & $1,71 \%$ & $8,55 \%$ \\
\hline Regular & $19,66 \%$ & $0,85 \%$ & $2,14 \%$ & $22,65 \%$ \\
\hline Bom & $23,93 \%$ & $0,43 \%$ & $2,56 \%$ & $26,92 \%$ \\
\hline Ótimo & $26,07 \%$ & $2,14 \%$ & $2,99 \%$ & $31,20 \%$ \\
\hline Total Vínculo & $\mathbf{8 6 , 3 2 \%}$ & $\mathbf{3 , 8 5 \%}$ & $\mathbf{9 , 8 3 \%}$ & $\mathbf{1 0 0 , 0 0 \%}$ \\
\hline
\end{tabular}




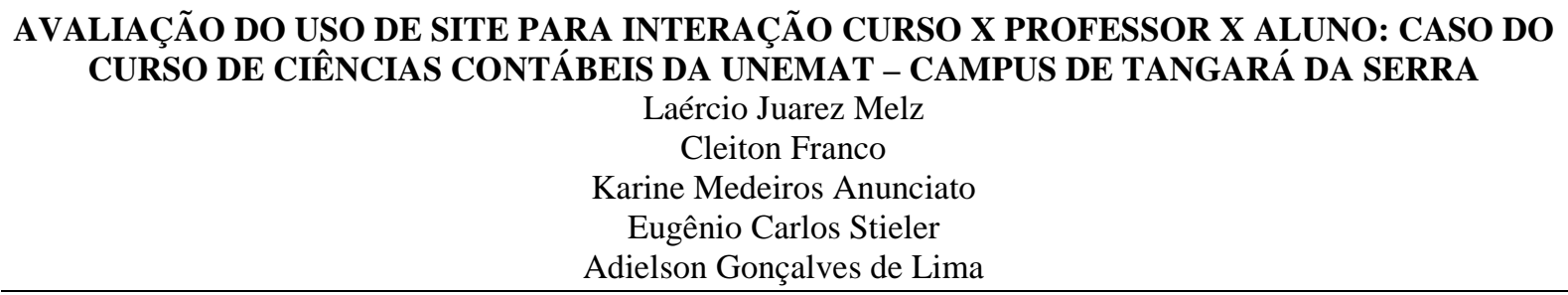

Em avaliação conjunta dos quesitos avaliados, percebe-se que o item que concentra maior parte de respostas positivas, bom ou ótimo, é o 'simplicidade e clareza', com 65,81\%. Em seguida 'organização dos conteúdos'. O quesito com maior número de avaliações negativas foi 'balcão de empregos', com 35,9\% de avaliações entre péssimo e ruim ().

Tabela 15 - Resumo das avaliações positivas e negativas dos quesitos.

\begin{tabular}{c|c|c|c|c|c|c|c|c}
\hline Quesitos avaliados & Péssimo & Ruim & Regular & Bom & Ótimo & $(-)$ & Neutras & $(+)$ \\
\hline Simplicidade e clareza & $7,26 \%$ & $6,41 \%$ & $20,51 \%$ & $33,76 \%$ & $32,05 \%$ & $13,68 \%$ & $20,51 \%$ & $65,81 \%$ \\
\hline $\begin{array}{c}\text { Organização dos } \\
\text { conteúdos }\end{array}$ & $10,26 \%$ & $7,26 \%$ & $21,37 \%$ & $31,20 \%$ & $29,91 \%$ & $17,52 \%$ & $21,37 \%$ & $61,11 \%$ \\
\hline Informações sobre o curso & $10,68 \%$ & $8,55 \%$ & $22,65 \%$ & $26,92 \%$ & $31,20 \%$ & $19,23 \%$ & $22,65 \%$ & $58,12 \%$ \\
\hline $\begin{array}{c}\text { Divulgação de ações do } \\
\text { Departamento }\end{array}$ & $10,26 \%$ & $8,12 \%$ & $24,36 \%$ & $30,77 \%$ & $26,50 \%$ & $18,38 \%$ & $24,36 \%$ & $57,26 \%$ \\
\hline $\begin{array}{c}\text { Disponibilidade de } \\
\text { materiais }\end{array}$ & $8,97 \%$ & $10,68 \%$ & $27,35 \%$ & $26,92 \%$ & $26,07 \%$ & $19,66 \%$ & $27,35 \%$ & $52,99 \%$ \\
\hline Publicações & $9,40 \%$ & $11,97 \%$ & $27,78 \%$ & $28,63 \%$ & $22,22 \%$ & $21,37 \%$ & $27,78 \%$ & $50,85 \%$ \\
\hline Aparência & $14,53 \%$ & $12,39 \%$ & $26,50 \%$ & $21,37 \%$ & $25,21 \%$ & $26,92 \%$ & $26,50 \%$ & $46,58 \%$ \\
\hline Balcão de empregos & $19,23 \%$ & $16,67 \%$ & $24,36 \%$ & $26,07 \%$ & $13,68 \%$ & $35,90 \%$ & $24,36 \%$ & $39,74 \%$ \\
\hline
\end{tabular}

Ao final do questionário o respondente poderia deixar sugestões e comentários. Após análise, verificou-se que o principal uso foi para sugestões de melhoria. A principal sugestão é a ordenação dos materiais em ordem cronológica. Observou-se que a sugestão não pode ser realizada por limitação técnica. O site ordena os arquivos em ordem alfabética, portanto, seria necessário acrescentar a data no nome do arquivo em formato aaa-mm-dd para ordenar de forma cronológica. Foram computadas 11 criticas negativa nos comentários e 10 críticas positivas e 1 comentário fora de contexto. O total de comentários foi de 51, representando $21,79 \%$ dos respondentes (Tabela 16). Algumas sugestões puderam ser realizadas outras dependem de conscientização do professor, transcritas literalmente no Quadro 3.

Tabela 16 - Sugestões e comentários deixados no site.

\begin{tabular}{c|c|c|c|c|c}
\hline Tipo de comentário & Negativa & Positiva & Sugestão & Comentário & Total geral \\
\hline Conscientização do professor & & & 3 & & 3 \\
\hline Não realizado & & & 15 & & 15 \\
\hline Não relacionada ao site & 1 & & 1 & & 2 \\
\hline Realizado & & & 9 & & 9 \\
\hline Não se aplica & 11 & 10 & & 1 & 22 \\
\hline Total Geral & $\mathbf{1 2}$ & $\mathbf{1 0}$ & $\mathbf{2 8}$ & $\mathbf{1}$ & $\mathbf{5 1}$ \\
\hline
\end{tabular}

Quadro 3 - Transcrição literal das sugestões realizadas e que dependem de conscientização do professor.

Realizados

\begin{tabular}{|l|l|}
\hline "Sugestão: na grade curricular de cada disciplina deveria indicar uma bibliografia básica." \\
\hline "Comunicação aberta e mais variada."
\end{tabular}




\begin{tabular}{|c|c|}
\hline \multicolumn{2}{|c|}{$\begin{array}{c}\text { Cleiton Franco } \\
\text { Karine Medeiros Anunciato } \\
\text { Eugênio Carlos Stieler } \\
\text { Adielson Gonçalves de Lima }\end{array}$} \\
\hline & "Deveria ter a ementa de todos os semestres" \\
\hline & "Ementas e as monografias de anos anteriores" \\
\hline & $\begin{array}{l}\text { "Incluir o horário de funcionamento do dpto de ciências contábeis, bem como instruções } \\
\text { referente a solicitação para cursar diciplina em outro curso (o que é necessário,etc...)" }\end{array}$ \\
\hline & "Incluir telefone e ramal para contato junto ao dpto" \\
\hline & "Mude a cor do site, coloque a cor padrão do curso."rosa"” \\
\hline & $\begin{array}{l}\text { "Organizar por data os avisos, as vezes tenho a necessidade de procurar determinado aviso } \\
\text { e perco tempo procurando por páginas aleatórias." }\end{array}$ \\
\hline & "Separar as informações por semestre" \\
\hline \multirow{3}{*}{$\begin{array}{l}\text { Conscientização do } \\
\text { professor }\end{array}$} & $\begin{array}{l}\text { "Seria interessante que os professores postassem os conteudos que serão estudos em sala } \\
\text { de aula com mais antecedencia , por que varias vezes eles postam sempre no final da tarde } \\
\text { quando saimos do serviço e vamos pra casa apenas pra tomar banho e ir pra faculdade." }\end{array}$ \\
\hline & "Cobrar mais dos professores a regularidade das disposições de materiais e notas." \\
\hline & $\begin{array}{l}\text { "Adesão total dos professores em divulgar no site todas as notas de avaliações ocorridas e } \\
\text { inclusive publicando a data das principais avaliações. Dando mais praticidade ao acesso } \\
\text { das notas pelos alunos." }\end{array}$ \\
\hline
\end{tabular}

\section{CONSIDERAÇÕES FINAIS}

Iniciativas que facilitem a comunicação entre coordenação de curso, professores e alunos devem ser sempre incentivadas. Percebe-se que existem recursos que não têm custo nenhum, seja para criação de websites, para coleta de dados, ou análise do fluxo de visitantes. O site analisado e o próprio artigo são prova dessa afirmação.

Conclui-se que o número de acessos tem aumentado ao longo dos meses analisados, principalmente no período letivo. O site foi bem avaliado na maioria dos quesitos respondidos, principalmente no que tange à simplicidade e clareza e à organização dos conteúdos.

Sugere-se melhorar os itens com avaliações negativas: balcão de empregos; aparência; publicações. Sugere-se, adicionalmente, que novos conteúdos no site sejam amplamente divulgados para aumentar o interesse dos usuários em acessar as novas páginas.

\section{REFERÊNCIAS}

ANTONIOLI, L. Estatísticas, dados e projeções atuais sobre a internet no Brasil, 2011.

Disponivel em: 〈http://www.tobeguarany.com/internet_no_brasil.php>. Acesso em: 16 abr 2011.

BARBERO, J. M. Desafios culturais da comunicação a educação. Comunicação \& Educação, São Paulo, v. 6, n. 18, p. 51-61, maio/ago 2000. Disponivel em: 
AVALIAÇÃO DO USO DE SITE PARA INTERAÇÃO CURSO X PROFESSOR X ALUNO: CASO DO

CURSO DE CIÊNCIAS CONTÁBEIS DA UNEMAT - CAMPUS DE TANGARÁ DA SERRA

Laércio Juarez Melz

Cleiton Franco

Karine Medeiros Anunciato

Eugênio Carlos Stieler

Adielson Gonçalves de Lima

<http://www.revistas.univerciencia.org/index.php/comeduc/article/viewFile/4108/3860>.

Acesso em: 11 out 2012.

BASTIEN, C.; SCAPIN, D. Rapport Technique 0156: Ergonomic Criteria for the evaluation of human-computer interfaces. Rocquencourt: INRIA, 1993.

CETIC.BR. Centro de Estudos sobre as Tecnologias da Informação e da Comunicação.

Painel IBOPE/NetRatings, 2011. Disponivel em:

<http://www.cetic.br/usuarios/ibope/index.htm>. Acesso em: 16 abr 2011.

CONTÁBEIS. Departamento de Ciências Contábeis. Universidade do Estado de Mato

Grosso. Departamento de Ciências Contábeis - UNEMAT - Tangará da Serra, 2012.

Disponivel em: <http://tangara.unemat.br/contabeis>. Acesso em: 11 out 2012.

FLEMING, J. Web navigation: designing the user experience. Cambridge: O'Reilly, 1998.

GOOGLE. Google Analytics, 2012a. Disponivel em: <http://www.google.com/analytics>. Acesso em: 11 out 2012a.

GOOGLE. Google Drive, 2012b. Disponivel em: <http://drive.google.com>. Acesso em: 11 out $2012 b$.

MARTINS, C. G.; FERREIRA, M. L. R. O survey como tipo de pesquisa aplicado na descrição do conhecimento do processo de gerenciamento de riscos em projetos no segmento da construção. VII Congresso Nacional de Excelência em Gestão, 12 e 13 ago 2011. Disponivel em: <http://www.excelenciaemgestao.org/Portals/2/documents/cneg7/anais/T11_0362_1839.pdf> . Acesso em: 11 ago 2012.

MAYHEW, D. Principles and guidelines in software user interface design. New Jersey: Prentice Hall, 1992.

MORAN, J. M. Como utilizar a Internet na educação. Ciência da Informação, Brasilia, v. 26, n. 2, maio-ago 1997. ISSN 0100-1965.

MOREIRA, D. A. (. Didática do Ensino Superior: Técnicas e Tendências. São Paulo: Pioneira Thomson Learning, 2003.

NÉRICI, I. G. Metodologia do ensino: uma introdução. 4. ed. São Paulo: Atlas, 1992.

NIELSEN, J. Usability engineering. San Diego: Morgan Kaufmann, 1993.

PETTERSON, R. It Depends: ID - principles and guidelines. Tullinge: Institute for Infology, 2007. 
AVALIAÇÃO DO USO DE SITE PARA INTERAÇÃO CURSO X PROFESSOR X ALUNO: CASO DO CURSO DE CIÊNCIAS CONTÁBEIS DA UNEMAT - CAMPUS DE TANGARÁ DA SERRA

Laércio Juarez Melz Cleiton Franco

Karine Medeiros Anunciato

Eugênio Carlos Stieler

Adielson Gonçalves de Lima

RAUPP; MAURY; BEUREN, I. M. Metodologia da pesquisa aplicável às ciências sociais.

In: BEUREN, I. M. (. ). Como elaborar trabalhos monográficos em contabilidade: teoria e prática. São Paulo: Atlas, 2003. Cap. 3, p. 76-97.

REDIG, J. Design é metodologia: procedimentos próprios do dia-a-dia do designer. In:

COELHO, L. A. Design Método. Rio de Janeiro: PUC-Rio; Novas Idéias, 2006. p. 169-178.

ROSENFELD, L.; MORVILLE, P. Information Architecture for the World Wide Web.

New York: O’Reilly, 1998.

YIN, R. K. Case study research: design and methods. 2. ed. USA: Sage Publication, 1994. 